\title{
Penerapan Metode Forward Chaining dalam Perancangan Sistem Pakar Tes Emotional Quotient (EQ) Berbasis Web
}

\author{
Anggia Dasa Putri ${ }^{1 *}$, Ellbert Hutabri ${ }^{2 * *}$ \\ * Teknik Informatika, Universitas Putra Batam \\ anggiaputri4@gmail.com ${ }^{1}$, ellbert.hutabri@gmail.com ${ }^{2}$
}

\begin{tabular}{l} 
Article Info \\
\hline Article history: \\
Received 2019-10-11 \\
Revised 2019-11-04 \\
Accepted 2019-11-25 \\
\hline
\end{tabular}

Keyword:

Expert system, Emotional Quotient, Forward Chaining, UML.

\begin{abstract}
Humans as social beings who must interact with various other individual character types must have emotional intelligence. Emotional intelligence is not the same person, intelligence is influenced by the family environment, age, and physical. High or low emotional intelligence influences how to interact and work. Individuals who have low emotional intelligence tend to have individualistic traits and cannot work together in teams, for that every company or agency needs to conduct tests on prospective employees. IQ and EQ tests conducted by companies to prospective employees so far have been done manually, so that problems often occur such as the test taker takes a long time to correct answer sheets, errors in calculating scores and reports of long test results when the test participants are in the amount big. Given the company's mistakes are often too late and wrong in making decisions to accept the right employees, for that we need to make an expert system that can help companies in conducting EQ tests for the selection process of prospective employees in accordance with the desired criteria. Expert system that is designed using the method of forward chaining is a method of searching or tracking information starting from existing information and combined with the rules to get a conclusion. Expert System Design uses an object oriented approach and PHP programming language so that it can be used to help companies, especially in the Human Resource Department (HRD) in the selection of prospective employees.
\end{abstract}

Copyright (C) 2019 Journal of Applied Informatics and Computing. All rights reserved..

\section{Pendahuluan}

Kota Batam yang merupakan kota industri, secara geografis berada pada bagian terluar Negara Indonesia, diuntungkan dengan berbatasan langsung dengan beberapa negara tetangga. Karena letak Kota Batam yang sangat strategis, memicu para penanam modal baik dari dalam maupun luar negeri untuk investasi pada sektor industri. Dengan banyaknya industri di Kota Batam, menarik perhatian bagi pencari kerja dari berbagai daerah di Indonesia maupun manca negara, sehingga perlu dilakukan seleksi agar mendapatkan tenaga kerja yang tepat dan sesuai dengan kompetensinya. Bagian Human Resources Departement (HRD) harus memperhatikan berbagai aspek yang dimiliki oleh calon karyawan yang akan direkrut, salah satunya adalah kercerdasan emosional atau biasa disebut sebagai Emotional Quotient (EQ). Kecerdasan emosional adalah kemampuan untuk memahami perasaan diri sendiri dan orang lain, kemampuan untuk memotivasi dirinya sendiri dan menata emosi yang muncul dari dalam diri sendiri ketika berhubungan dengan orang lain dan lingkungannya [1].

Berdasarkan penelitian bahwa kecerdasan emosional seseorang mempunyai pengaruh secara signifikan terhadap kinerja karyawan [2]. Hal ini dikarenakan self awarness yang dimiliki oleh seorang karyawan semakin baik dimana karyawan tersebut akan memiliki kecenderungan berperilaku sesuai dengan standar yang telah ditetapkan oleh sebuah organisasi. Apabila organisasi menerapkan distribusi kerja dan memvisualkan beban kerja [3] secara adil dan sesuai dengan skill atau keterampilan yang dimiliki. Sedangkan Sapoto [4] berpendapat dalam penelitiannya bahwa kecerdasan emosional mampu meningkatkan keterampilan seseorang dalam menyelesaikan masalah serta konflik pribadi ecara efektif.

Selain itu juga penelitian lain menjelaskan bahwa kecerdasan intelijen (IQ) menentukan tingkat kesusksesan seseorang sebesar $20 \%$, sedangkan pada kecerdasan esmosional memberikan pengaruh sebesar $80 \%$ [5]. 
Sehingga ketika dalam kegiatan perekrutan karyawan harus dilakukan tes untuk kedua kecerdasaran tersebut.

Pada sebuah perusahaan selalu melakukan tes terhadap kecerdasan yang dimiliki oleh calon karyawan barunya, menurut pakar pada penelitian ini tes yang umumnya dilakukan adalah terhadap kecerdasan intelijen (IQ) dan tes kecerdasan emosional (EQ) tujuannya adalah agar calon karyawan yang nantinya akan bekerja memiliki kecakapan secara intelektual maupun secara emosional. Tes EQ diberikan pada calon karyawan yang sudah memenuhi kriteria secara administrasi, tes ini biasanya dilakukan pada satu hari. Untuk melakukan tes pada calon karyawan baru sebuah perusahan harus mengeluarkan dana yang cukup besar seperti biaya memperbanyak lembar soal, biaya memperbanyak lembar jawaban, biaya panitia seleksi serta biaya untuk panitia koreksi jawaban.

Selain biaya yang cukup besara, kendala yang mucul adalah apabila jumlah peserta yang ikut tes cukup banyak, maka membutuhkan waktu yang lama untuk mengoreksi jawaban tersebut, adanya kesalahan yang terjadi dalam proses koreksi, sering terjadi salah input nilai. Dengan adanya masalah-masalah tersebut maka akan membuat kemungkinan terjadi kesalahan kesalahan dalam meluluskan calon karyawan, sehingga ada beberapa karyawan lulus tidak sesuai dengan yang diharapkan cukup besar dikarenakan pihak HRD akan kesulitan. Untuk mengatasi masalah tersebut perlu dibuat suatu sistem pakar yang dapat membantu HRD di dalam sebuah perusahaan untuk melakukan tes EQ kepada calon karyawan baru, agar calon karyawan yang diterima dapat sesuai dengan kualifikasi yang dinginkan oleh perusahaan tersebut.

Sistem pakar merupakan salah satu bagian kecerdasan buatan yang mempelajari bagaimana mengadopsi seorang pakar berfikir dan menganalisa untuk menyelesaikan suatu masalah berdasarkan fakta-fakta yang ada dilapangan [6]. Sistem pakar juga merupakan program AI (Artificial Inteliigent) yang memiliki basis pengetahuan yang diperoleh dari pengalaman atau pengetahuan pakar dalam memecahkan suatu masalah pada bidang tertentu dan didukung mesin inferensi penalaran atau pelacakan terhadap fakta atau kaidah yang terdapat pada basis pengetahuan [7]. Salah satu metode yang dapat diterapkan dalam suatu sistem pakar adalah forward chaining yang digunakan untuk membuat rule sistem pakar. Berdasarkan masalah yang telah dijelaskan maka peneliti mencoba untuk melakukan penelitian perancangan sistem pakar tes emotional quotient dengan harapan dapat membantu bagian kepegawaian (HRD) dalam memperoleh karyawan yang tepat.

\section{METODE PENELITIAN}

Penelitian ini menggunakan metode fordward chaining dan diimplementasikan dalam bentuk aplikasi yang berbasis web. Sedangkan untuk perancangan sistem [8] menggunakan UML (Unified Modeling Language). UML merupakan bahasa standar yang dimanfaatkan untuk mendapatkan dokumentasi, spesifikasi dan membangun perangkat lunak
[9]. Metode penelitian ini dijelaskan pada desain penelitian, gambar 1 sebagai berikut.

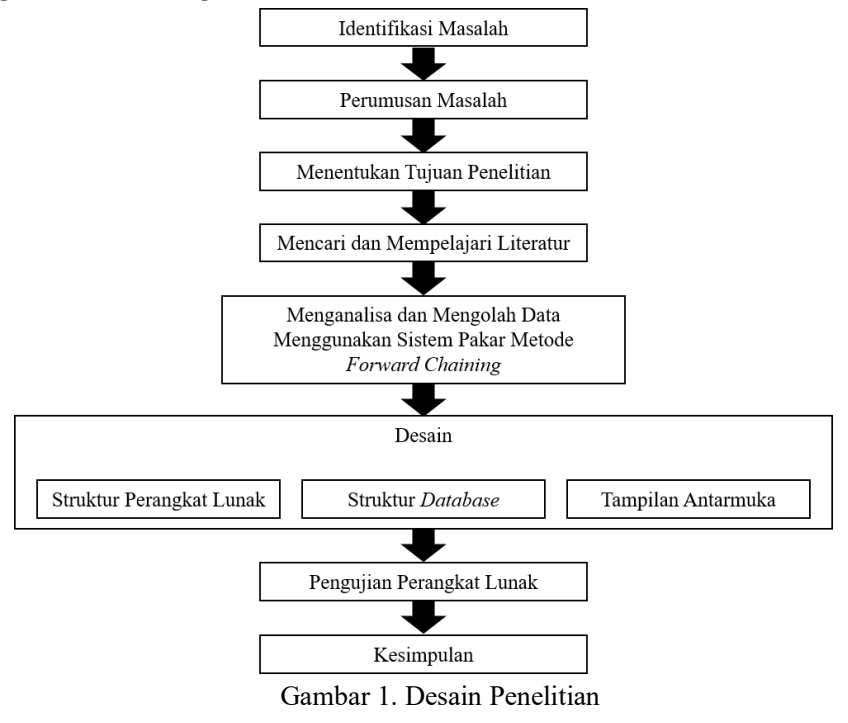

Gambar 1 menjelaskan desain penelitian dimana tahapantahapan penelitian yang akan dilakukan. Mulai dari melakukan identifikasi masalah, perumusan masalah, menentukan tujuan menganalisa dan mengolah data, mendesain system (perangkat lunak, integrasi database [10] dan tampilan antar muka), serta tahap akhir pengujian system. Hasil dari setiap tahapan akan diproses pada tahap selanjutnya sehingga sistem pakar yang dirancang dapat membantu HRD dalam menyelesaikan pekerjaan dengan mudah. Berdasarkan hasil wawancara yang dilakukan dengan pakar, ditemukan beberapa indikator untuk menentukan kecerdasaran emosional yang harus dimiliki oleh seorang calon karyawan dijelaskan pada tabel 1 sebagai berikut.

TABEL I

INDIKATOR KECERDASAN EMOSIONAL

\begin{tabular}{|c|l|}
\hline Nomor & \multicolumn{1}{c|}{ Indikator } \\
\hline 1. & Tingkat Kesadaran diri Tinggi \\
\hline 2. & Tingkat Kesadaran diri Rendah \\
\hline 3. & Tingkat Pengaturan diri Tinggi \\
\hline 4. & Tingkat Pengaturan diri Rendah \\
\hline 5. & Tingkat Motivasi Tinggi \\
\hline 6. & Tingkat Motivasi Rendah \\
\hline 7. & Tingkat Empati Tinggi \\
\hline 8. & Tingkat Empati Rendah \\
\hline 9. & Tingkat Keterampilan Sosial Tinggi \\
\hline 10. & Tingkat Keterampilan Sosial Rendah \\
\hline
\end{tabular}

Sepuluh indikator pada tabel 1 diturunkan menjadi basis pengetahuan yang dijelaskan pada tabel 2 sebagai berikut.

TABEL II

TABEL TINGKAT EMOSIONAL DAN SARAN

\begin{tabular}{|c|l|l|}
\hline Kode & $\begin{array}{c}\text { Tingkat } \\
\text { Emosional }\end{array}$ & Saran yang diberikan Pakar \\
\hline TE01 & Tingkat & Pertahankan rasa kesadaran diri \\
\hline
\end{tabular}




\begin{tabular}{|c|c|c|}
\hline & $\begin{array}{l}\text { Kesadaran diri } \\
\text { tinggi }\end{array}$ & yang telah anda miliki \\
\hline TE02 & $\begin{array}{l}\text { Tingkat } \\
\text { Kesadaran diri } \\
\text { rendah }\end{array}$ & $\begin{array}{l}\text { Mulailah memahami emosi yang } \\
\text { sedang dirasakan, kritis terhadap } \\
\text { informasi mengenai diri anda sendiri } \\
\text { dan menyadari tentang diri anda } \\
\text { yang nyata }\end{array}$ \\
\hline TE03 & $\begin{array}{l}\text { Tingkat } \\
\text { Pengaturan diri } \\
\text { Tinggi }\end{array}$ & $\begin{array}{l}\text { Pertahankan sifat pengaturan diri } \\
\text { anda yang sudah baik }\end{array}$ \\
\hline TE04 & $\begin{array}{l}\text { Tingkat } \\
\text { Pengaturan diri } \\
\text { Rendah }\end{array}$ & $\begin{array}{l}\text { Mulailah menangani emosi anda } \\
\text { sehingga berdampak positif kepada } \\
\text { pelaksanaan tugas }\end{array}$ \\
\hline TE05 & $\begin{array}{l}\text { Tingkat Motivasi } \\
\text { Tinggi }\end{array}$ & $\begin{array}{l}\text { Pertahankan sifat motivasi yang } \\
\text { anda miliki untuk memotivasi diri } \\
\text { sendiri dan orang- orang di sekitar } \\
\text { anda }\end{array}$ \\
\hline TE06 & $\begin{array}{l}\text { Tingkat Motivasi } \\
\text { Rendah }\end{array}$ & $\begin{array}{l}\text { Mulailah memotivasi anda sendiri } \\
\text { dan sering mendengarkan } \\
\text { ceramah atau seminar yang di } \\
\text { adakan para motivator sehingga } \\
\text { sedikit demi sedikit anda akan } \\
\text { termotivasi }\end{array}$ \\
\hline TE07 & $\begin{array}{l}\text { Tingkat Empati } \\
\text { Tinggi }\end{array}$ & $\begin{array}{l}\text { Pertahankan sifat empati yang anda } \\
\text { miliki demi menjalin baik hubungan } \\
\text { terhadap orang lain }\end{array}$ \\
\hline TE08 & $\begin{array}{l}\text { Tingkat Empati } \\
\text { Rendah }\end{array}$ & $\begin{array}{l}\text { Mulailah berinteraksi dengan orang- } \\
\text { orang di sekitar anda untuk menjalin } \\
\text { baik hubungan terhadap orang lain }\end{array}$ \\
\hline TE09 & $\begin{array}{l}\text { Tingkat } \\
\text { Keterampilan } \\
\text { Sosial Tinggi } \\
\end{array}$ & $\begin{array}{l}\text { Pertahankan sifat keterampilan } \\
\text { sosial anda yang sudah baik }\end{array}$ \\
\hline TE10 & $\begin{array}{l}\text { Tingkat } \\
\text { Keterampilan } \\
\text { Sosial Rendah }\end{array}$ & $\begin{array}{l}\text { Mulailah aktif dalam suatu diskusi } \\
\text { dan saling bertukar pendapat } \\
\text { sehingga mendapatkan hasil yang } \\
\text { memuaskan }\end{array}$ \\
\hline
\end{tabular}

Berdasarkan indikator yang diberikan oleh pakar, maka indikator tabel 1 tersebut perlu diberikan kode. Untuk lebih jelas dapat dilihat pada tabel 3 sebagai berikut.

TABEL III

TABEL GEJALA/ SIFAT

\begin{tabular}{|l|l|}
\hline Kode & \multicolumn{1}{|c|}{ Gejala / Sifat } \\
\hline KD01 & Anda Menyadari ketika anda kehilangan kontrol \\
\hline KD02 & Anda mengakui adanya kelemahan dan kekuatan pada \\
\hline KD03 & Anda meragukan kemampuan diri sendiri \\
\hline KD04 & Anda tidak mempunyai tujuan yang menantang \\
\hline KD05 & Anda membiarkan rintangan yang mengganggu \\
\hline PD01 & Anda belajar dari kemunduran \\
\hline PD02 & $\begin{array}{l}\text { Anda mematuhi nilai-nilai yang ada pada dirimu } \\
\text { bahkan ketika ada cobaan/tantangan }\end{array}$ \\
\hline PD03 & Anda tetap bersifat positif dalam situasi apapun \\
\hline PD04 & Anda membuat pekerjaan itu menjadi beban atau \\
\hline PD05 & Anda tidak mengetahui resiko dalam mengerjakan \\
\hline MD01 & $\begin{array}{l}\text { Anda yakin bahwa hari esok akan lebih baik dari hari } \\
\text { kemarin }\end{array}$ \\
\hline
\end{tabular}

\begin{tabular}{|l|l|}
\hline MD02 & $\begin{array}{l}\text { Anda berinisiatif mengambil tindakan untuk } \\
\text { menciptakan berbagai kemungkinan }\end{array}$ \\
\hline MD03 & Anda percaya diri mampu untuk melakukan suatu \\
\hline MD04 & Di dalam suatu kelompok, Anda bersikap pasif \\
\hline MD05 & Anda tidak mempunyai harapan yang besar \\
\hline EP01 & Anda mempunyai perhatian tentang tingkah laku \\
\hline EP02 & Anda melibatkan diri menjadi pendengar yang baik \\
\hline EP03 & $\begin{array}{l}\text { Anda berhubungan baik dengan orang lain yang } \\
\text { memiliki latar belakang yang berbeda }\end{array}$ \\
\hline EP04 & Anda tidak mengenali kemampuan khusus orang lain \\
\hline EP05 & Anda selalu menghindar diri dari orang lain \\
\hline KS01 & Anda memberi umpan balik yang bersifat membangun \\
\hline KS02 & Anda mengajak orang lain untuk peran serta \\
\hline
\end{tabular}

Berdasarkan tabel indikator di atas menjelaskan bahwa terdapat kaitan antara gelaja atau sifat yang dimiliki seseorang dengan kecerdasan emosional yang dimilikinya. Sehingga dapat dituangkan dalam bentuk atauran atau rule sistem pakar seperti tabel nomor 4 berikut.

TABEL IV

TABEL KAIDAH ATURAN (RULE)

\begin{tabular}{|c|c|}
\hline Kode Indikator & Kode Gejala/ Sifat \\
\hline TE01 & KD01, KD02, KD03 \\
\hline TE02 & KD04, KD05 \\
\hline TE03 & PD01, PD02, PD03 \\
\hline TE04 & PD04, PD05 \\
\hline TE05 & MD01, MD02, MD03 \\
\hline TE06 & MD04, MD05 \\
\hline TE07 & EP01, EP02, EP03 \\
\hline TE08 & EP04, EP05 \\
\hline TE09 & KS01, KS02, KS03 \\
\hline TE10 & KS04, KS05 \\
\hline
\end{tabular}

Berdasarkan data aturan yang telah disusun di tabel 4, maka kaidah aturan (rule) yang digunakan dalam sistem pakar adalah sebagai berikut.

- Kaidah 1: IF KD01 AND KD02 AND KD03 THEN TE01

- Kaidah 2: IF KD04 AND KD05 THEN TE02

- Kaidah 3: IF PD01 AND PD02 AND PD03 THEN TE03

- Kaidah 4: IF PD04 AND PD05 THEN TE04

- Kaidah 5: IF MD01 AND MD02 AND MD03 THEN TE05

- Kaidah 6: IF MD04 AND MD05 THEN TE06

- Kaidah 7: IF EP01 AND EP02 AND EP03 THEN TE07

- Kaidah 8: IF EP04 AND EP05 THEN TE08

- Kaidah 9: IF KS01 AND KS02 AND KS03 THEN TE09

- Kaidah 10: IF KS04 AND KS05 THEN TE10

Berdasarkan kaidah (rule) yang telah dibuat maka dapat dijelaskan bahwa:

1) Jika sifat orang tersebut adalah sadar ketika kehilangan kontrol, mengakui dirinya memiliki kelemahan dan 
kekuatan, dan meragukan kemampuan dirinya sendiri maka tingkat kesadaran diri tinggi.

2) Jika sifat orang tersebut adalah tidak mempunyai tujuan yang menantang, membiarkan rintangan yang mengganggu tujuanmu maka tingkat kesadaran diri rendah.

3) Jika sifat orang tersebut adalah selalu belajar dari kemunduran, mematuhi nilai-nilai yang ada pada dirimu bahkan ketika ada cobaan/tantangan, dan Anda tetap bersifat positif dalam situasi apapun maka tingkat Pengaturan diri tinggi.

4) Jika sifat orang tersebut adalah selalu membuat pekerjaan itu menjadi beban atau stress, dan tidak mengetahui resiko dalam mengerjakan pekerjaan maka tingkat Pengaturan diri rendah.

5) Jika sifat orang tersebut adalah yakin bahwa hari esok akan lebih baik dari hari kemarin, berinisiatif mengambil tindakan untuk menciptakan berbagai kemungkinan, dan percaya diri mampu untuk melakukan suatu pekerjaan maka tingkat motivasi tinggi.

6) Jika sifat orang tersebut adalah pasif dalam suatu kelompok, dan tidak mempunyai harapan yang besar maka tingkat motivasi rendah.

7) Jika sifat orang tersebut adalah perhatian tentang tingkah laku orang lain, melibatkan diri menjadi pendengar yang baik, dan berhubungan baik dengan orang lain yang memiliki latar belakang yang berbeda maka tingkat empati tinggi.

8) Jika sifat orang tersebut adalah tidak mengenali kemampuan khusus orang lain, dan selalu menhindar diri dari orang lain maka tingkat empati rendah.

9) Jika sifat orang tersebut adalah memberi umpan balik yang bersifat membangun, mengajak orang lain untuk peran serta, dan memahami struktur informal dalam organisasi maka tingkat kesadaran sosial tinggi.

10) Jika sifat orang tersebut adalah tidak memahami aturan yang tak tertulis di dalam organisasi, dan tidak suka bekerja sama dengan orang lain maka tingkat kesadaran sosial rendah.

Sehingga dapat dibuat pohon keputusan dari kaidah atau rule tersebut. Pohon keputusan digunakan untuk membangun sistem pakar, di dalam pohon keputusan tersebut akan dicari solusi yang paling tepat untuk mendapatkan calon karyawan yang tepat. Diagram pohon keputusan akan mempermudah dalam menyusun basis pengetahuan dan aturan serta menentukan faktor kepastian dari setiap sistem pakar [11].

\section{HASIL PERANCANGAN DAN PEMBAHASAN}

\section{A. Use Case Diagram}

Use case diagram digunakan untuk memodelkan sistem pakar [12]. Use case bertujuan untuk menjelaskan hubungan antara pengguna atau aktor yang terlibat dengan sistem yang akan dibuat. Use case diagram sistem pakar tes kecerdasasn emosional (EQ) dapat dilihat pada gambar 2 sebagai berikut.

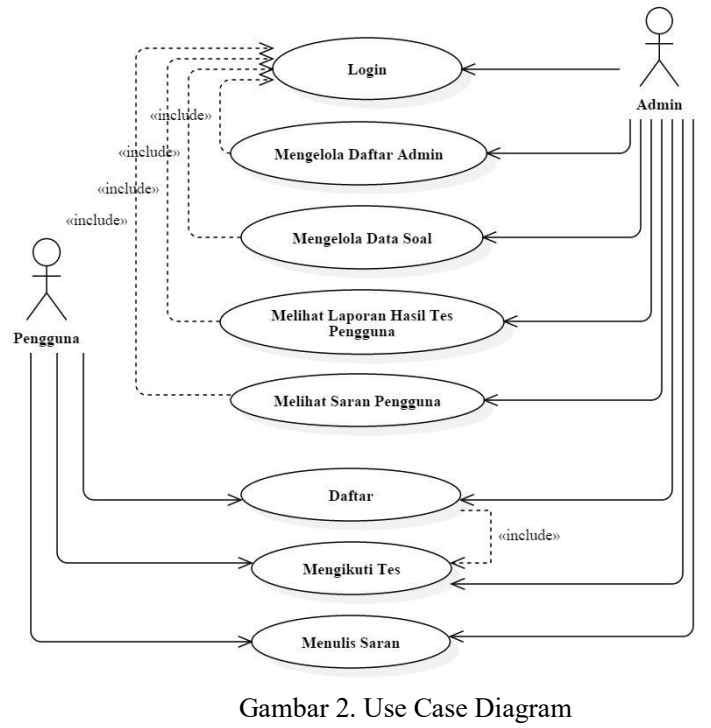

Gambar 2 menunjukkan use case diagaram dari sistem pakar yang dirancang. Aktor yang terlibat adalah Admin dan pengguna. Aktor admin mengelola soal tes EQ, mengelola data calon karyawan dan mengelola hasil tes. Sedangkan actor pengguna adalah calon karyawan yang dapat mendaftar untuk mendapatkan akun dan melakukan tes serta menulis saran (feedback) untuk admin.

\section{B. Activity Diagram}

Activity diagram bertujuan untuk menggambarkan aktivitas yang terjadi pada sistem [13]. Untuk lebih jelas activity diagram sistem pakar kecerdasan emosional dapat dilihat pada gambar 3 sebagai berikut.

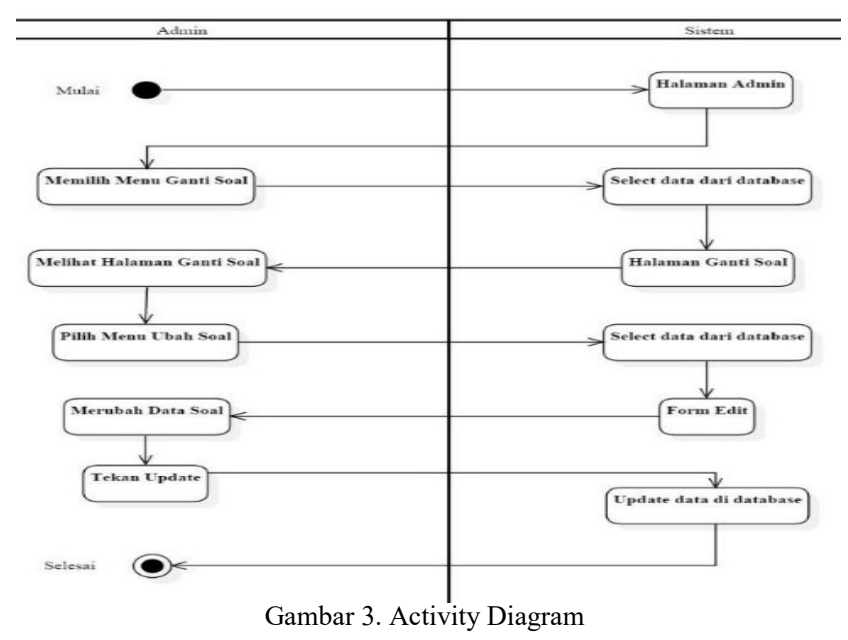




\section{Sequence Diagram}

Sequence Diagram menggambarkan hubungan timbal balik antara sistem dengan user, dimana sistem memberikan respon terhadap aktivitas yang dilakukan oleh user.

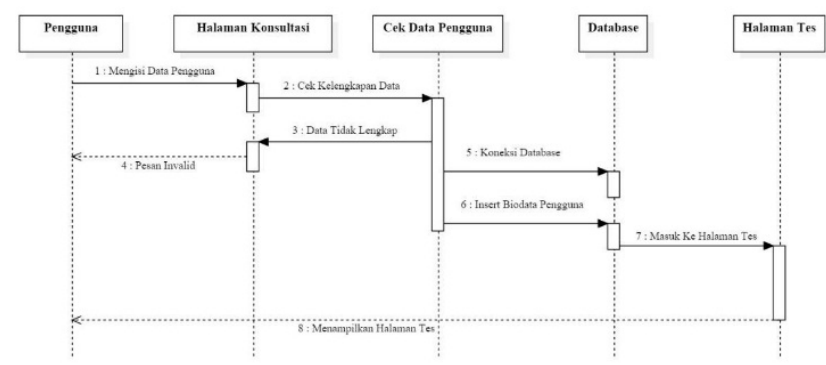

Gambar 4. Sequence Diagram

\section{Class Diagram}

Class Diagram menunjukan interaksi kelas-kelas ada dalam sistem pakar kecerdasan emosional (EQ). Dalam rancangan ini terdapat tujuh kelas yang saling berinteraksi satu sama lain untuk menunjang jalannya sistem.
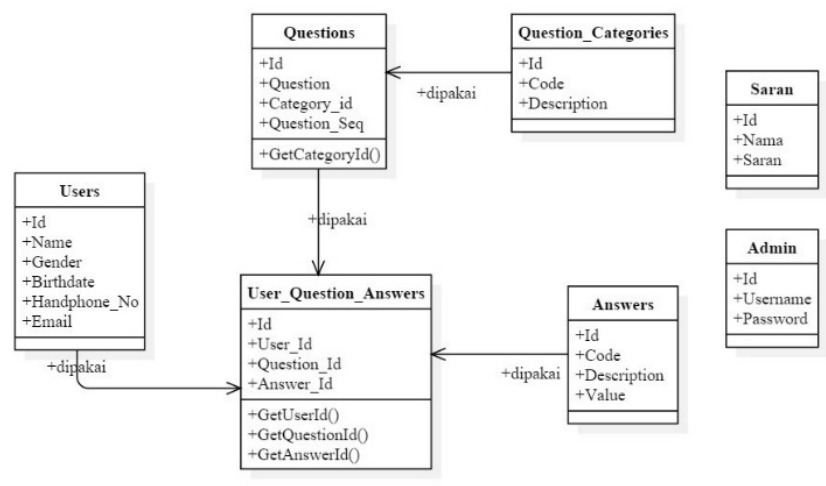

Gambar 5. Class Diagram

\section{E. Hasil Eksekusi Program}

Hasil akhir penelitian ini adalah sistem pakar untu tes kecerdasan emosional seorang calon karyawan berbasis web menggunakan forward chaining. Hasil eksekusi program berupa menu utama, halaman test dan hasil test. Menu Utama adalah menu yang muncul saat pertama kali pengguna menjalankan sistem.

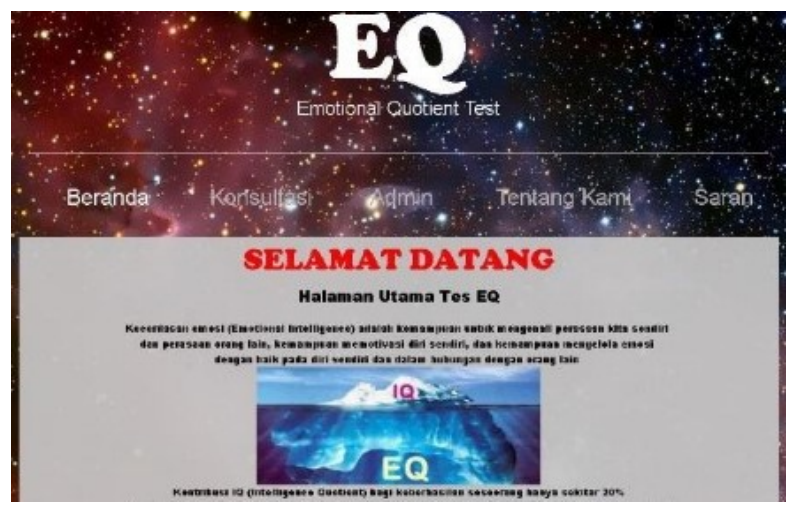

Gambar 6. Menu Utama
Setelah pengisian biodata, calon karyawan dapat melakukan tes dengan memilih menu konsultasi. Menu konsultasi dapat dilihat pada tampilan halaman test.

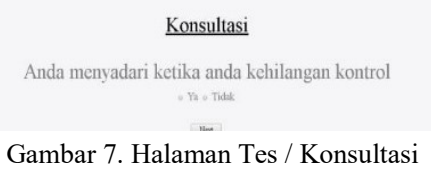

Halaman tes EQ atau disebut juga dengan halaman konsultasi merupakan halaman dimana calon karyawan menjawab pertanyaan yang sesuai dengan rule yang telah ditetapkan pada tahap analisis. Berdasarkan jawaban yang diberikan oleh peserta test dapat diambil suatu keputusan yang tepat oleh bagian HRD. Test kecerdasan emosional yang dilakukan oleh seluruh calon karyawan dapat dilihat oleh admin pada halaman hasil tes, seperti terlihat pada gambar 8 berikut ini.

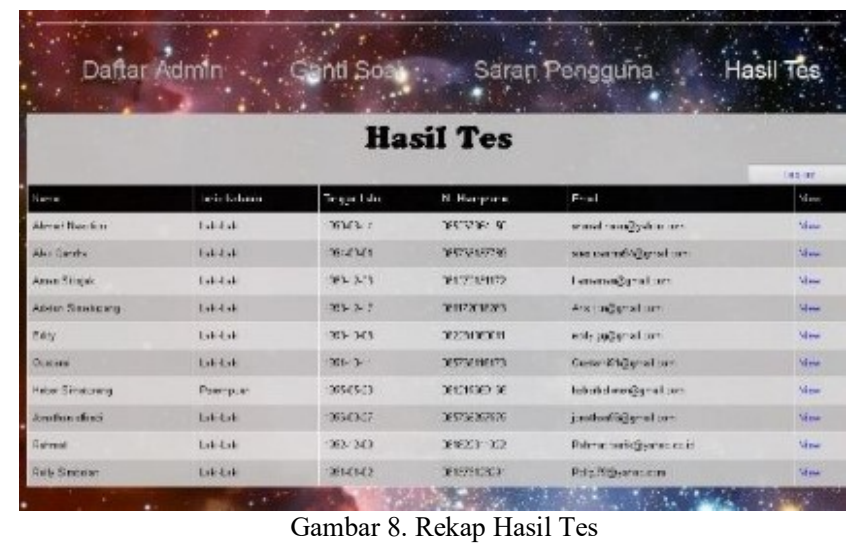

Halaman hasil tes berisikan data peserta tes yaitu nama, jenis kelamin, tanggal tes, dan hasil yang diperoleh, hasil tes ini yang akan diserahkan kepada bagian HRD untuk menentukan kelulusan peserta tes EQ. Harapannya agar bagian HRD dapat memutuskan dengan akurat, cepat dan tepat [14] sesuai dengan parameter kaidah (rule) yang telah ditentukan sebelumnya.

\section{KESIMPULAN}

Kecerdasan emosional seseorang sangat mempengaruhi kinerja untuk itu perlu dilakukan tes terhadap kecerdasan, agar bagian kepegawaian (HRD) dapat memperoleh karyawan yang mudah dan tepat. Sistem pakar tes kecerdasan emosional dirancang berdasarkan pemikiran dan analisis seorang pakar yang dibentuk ke dalam rule atau kaidah inferensi untuk menarik suatu keputusan yang tepat. Perancangan sistem menggunakan Unified Modelling Language (UML) untuk menggambarkan proses yang terjadi serta interaksi sistem dengan aktor. Diagram pada UML terdiri dari use case, activity dan class diagram menunjukkan skenario aktifitas yang dapat dilakukan oleh aktor. Hasil pengujian system mampu menjawab dan 
memtuskan sesuai dengan rule/kaidah yang telah ditetapkan. Harapannya bahwa sistem yang telah dikembangkan dapat membantu dalam mengatasi masalah yang terjadi ketika tes seperti masalah biaya dan masalah teknis lainnya, sehingga dapat membantu bagian kepegawaian (HRD) di perusahaan dalam mengambil keputusan yang cepat dan tepat karena sistem telah dapat menentukan kecerdasan calon karyawan dengan akurat sesuai parameter kaidah (rule) yang telah ditentukan.

\section{Daftar Pustaka}

[1] M. Gitosaroso, "Kecerdasan Emosi ( Emotional Intelligence )," $J$. Khatulistiwa, vol. 2, no. 2, pp. 182-200, 2012.

[2] T. Fitriastuti, "Pengaruh Kecerdasan Emosional, Komitmen Organisasional dan Oranizational Citizenship Behavior Terhadap Kinerja Karayawan,” J. Din. Manaj., vol. 5, no. 2, pp. 171-182, 2014.

[3] M. K. Mufida, M. Santiputri, N. Z. Janah, D. E. Kurniawan, and M. Idris, 'Lecturer Workload Optimization Applying Interactive Visualization', in IOP Conference Series: Materials Science and Engineering, 2018, vol. 407, no. 1, p. 12113

[4] R. Saptoto, "Hubungan Kecerdasan Emosi dengan Kemampuan Coping Adaptif," J. Psikol., vol. 37, no. 1, pp. 13-22, 2015.
[5] A. Nggermanto, Kecerdasan Quantum. Bandung: Nusa Cendikia, 2015

[6] A. D. Putri and D. Suhendra, "Sistem Pakar Untuk Mendeteksi Kerusakan Air Conditioner Menggunakan Metode Forward Chaining Berbasis Web," J. Inovtek Polbeg, vol. 1, no. 2, pp 146-160, 2016.

[7] H. Hayadi, Sistem Pakar. Deeppublish, 2016

[8] N. Z. Janah, Y. Rokhayati, D. E. Kurniawan, and M. F. Muvariz, 'Electronic School Books Dissemination Application for Batam Hinterland Schools', Adv. Sci. Lett., vol. 24, no. 12, pp. 9739 9744, 2018

[9] T. A. Kurniawan, "Pemodelan Use Case (UML): Evaluasi Terhadap beberapa Kesalahan dalam Praktik," J. Teknol. Inf. dan Ilmu Komput., vol. 5, no. 1, p. 77, 2018.

[10] D. Dhining, Y. Rokhayati, D. E. Kurniawan, and others, 'Penerapan Replikasi Data pada Aplikasi Ticketing Menggunakan Slony PostgreSQL', J. Appl. Informatics Comput., vol. 1, no. 2, pp. 9-18, 2017

[11] A. B. Prabowo, "Sistem Pakar Untuk Mendiagnosa Penyakit Infeksi Saluran Pernafasan Akut (ISPA) Berbasis Web," J. Sarj. Tek. Inform., vol. 2, no. 1, pp. 1-5, 2014.

[12] G. Urva, H. F. Siregar, J. Prof, M. Y. Kisaran, and S. Utara, "Pemodelan UML E- Marketing Minyak Goreng," no. 9, pp. 92$101,2015$.

[13] Y. Heriyanto, "Perancangan Sistem Informasi Rental Mobil Berbasis Web Pada PT. APM Rent Car," J. Chem. Inf. Model., vol. 53, no. 9, pp. 1689-1699, 2013 . 